\title{
Pathological Studies on Newcastle Disease: Laryngotracheal and Conjunctival Lesions Caused by So-Called Asian Type Newcastle Disease Virus
}

\author{
Hiromitsu KATOH \\ Osaka Municipal Poultry Experiment Station, Kawanabe-cho, \\ Higashi Sumiyoshi-ku, Osaka-shi, Osaka 546
}

(Received for publication December 6, 1975)

\begin{abstract}
Pathological studies were carried out on laryngotracheal and conjunctival lesions caused by experimental infection with so-called Asian type Newcastle disease virus. In them, strain 2440 of the virus was inoculated into two groups of chickens by the intratracheal and intra-ocular route. The same symptoms and gross lesions as those of the acute type in field outbreaks were observed in the birds of both groups during 3 to 6 days after inoculation. Prominent necrosis of the epithelium and lymphatic areas and mild to moderate proliferation of lymphoid cells were seen as characteristic changes in the organs studied. The course of epithelial necrosis was initiated by vacuolation of the cytoplasm, followed by the appearance of eosinophilic inclusions and the formation of a network inside the cytoplasm and terminated by the disintegration of epithelial cells into debris. Necrosis of the lymphoid area was similar to the change of lymphatic organs previously reported by this author.
\end{abstract}

Newcastle disease (ND) was first described by Doyle [1] and has been examined pathologically by various authors from different points of view. Jungherr et al. [6] made pathological comparison in details between fowl plague and so-called Asian type ND. Similar reports on pathological investigation of Asian type ND have been published by several workers $[2-5,10,12]$.

There has been, however, few works on pathological observation on laryngotracheal and conjunctival lesions caused by Asian type ND virus infection, because this virus might have been recognized as having an enterotropic nature.

Kawasaki et al. [9] reported that under gross observation hemorrhage was sometimes noticed in the conjunctiva of natu- rally infected chickens in addition to the occurrence of laryngotracheal and cloacal lesions. Recently, it was confirmed that birds infected experimentally with Asian type ND virus often associated with laryngotracheal lesions characterized by hemorrhage, necrosis and ulcer [11].

There has been, however, no reports describing the transition of laryngotracheal and conjunctival changes caused by Asian type ND virus infection.

The purpose of this paper is to report the laryngotracheal and conjunctival changes in chickens experimentally infected with Asian type ND virus. Pathological observation and immunofluorescent studies were made.

Present address: Ueno Fine Chemical Industries, Ltd., 1-127 Higashi-arioka, Itami-shi, Hyogo 664 ニューカッスル病の病理学的研究一アジア型ニューカッスル病に際する喉頭・気管および結膜の病変：加藤宏光 (大阪市立家禽試験場) 


\section{Materials and Methods}

\section{Materials}

Virus: ND virus used in the present study was strain 2440 which had been isolated from a field outbreak in 1967 at the author's station and identified as ND virus. The virus had been passed 6 times through chiken embryos before this experiment.

Chickens: Seventy-two White-leghorn chickens, 36 days old, were used. The hemagglutinationinhibition (HI) test was performed before the experiment and $\mathrm{HI}$ titers were found to be undetectable.

Direct fluorescent antibody technique: The direct fluorescent antibody technique of Kawasaki [8] was applied by using fluorescent-globulin prepared from chickens which had been infected with and recovered from Asian type ND.

2. Methods

The suspension of virus, strain 2440, was calculated to have an infective titer of $10^{8.5}$ TCID $_{\tilde{5} 0} /$ $0.1 \mathrm{~m} l$. Then a virus inoculum was prepared by diluting the suspension to $1: 1,000$ with PBS $(\mathrm{pH}$ $7.0)$ containing $200 \mathrm{mcg}$ of dihydrostreptomycin and $200 \mathrm{i} . \mathrm{u}$. of penicillin-G/1.0 m $\mathrm{l}$.

Seventy-two birds were divided into 2 groups of 36 birds each and placed separately in special isola- tion units.

Each bird of one group received intratracheal inoculation with $0.1 \mathrm{~m} l$ of the inoculum. On the same day each bird of the other group was inoculated intraocularly (into both eyes) with $0.05 \mathrm{ml}$ / eye of the inoculum.

Clinical observation was made for 6 days postinoculation. On each day of experiment, 4 to 6 birds were randomly selected from each group and subjected to necropsy. After gross observation was made, portions of the larynx, trachea and conjunctiva were taken and fixed in a $10 \%$ formalin solution. Thin sections of these portions were stained with hematoxylin and eosin for histopathological examination. The same tissues were also placed in $\mathrm{N}$-hexan refrigerated with a mixture of solid carbon dioxide and acetone, and sectioned by a cryostat for immunofluorescent examination.

\section{Results}

1. Clinical symptoms and gross pathology

Clinical symptoms and gross changes observed were generally identical to those reported in typical Asian-type ND infection. Symptoms noticed were green diarrhea, depression, tic and cyanosis of the comb.

Table 1. Symptoms and gross lesions of conjunctiva and larynx in two groups

\begin{tabular}{|c|c|c|c|c|c|c|}
\hline \multirow{2}{*}{$\begin{array}{l}\text { Groups } \\
\text { Days } \\
\text { after } \\
\text { inoculation }\end{array}$} & \multicolumn{3}{|c|}{ Intra-tracheal inoculation group } & \multicolumn{3}{|c|}{ Intra-ocular inoculation group } \\
\hline & Symptoms & Conjunctiva & Larynx & Symptoms & Conjunctiva & $\overbrace{\text { Larynx }}$ \\
\hline 1 & 0000 & 0000 & 0000 & 0000 & 0000 & 0000 \\
\hline 2 & 0000 & 0000 & $\triangle 1 D D$ & 0000 & $\triangle 100$ & 0000 \\
\hline 3 & -DDD & DDDD & $\triangle D D D$ & (1)DD & DDD(1) & ODDO \\
\hline 4 & $\begin{array}{lll}1 & 0 & 1 \\
0 & 0 & \oplus\end{array}$ & $\begin{array}{lll}0 & 0 & 0 \\
0 & 0 & 0\end{array}$ & & $\begin{array}{lll}\text { (1) } & (1) & (1) \\
\text { (1) } & \text { (1) } & 0\end{array}$ & & $\begin{array}{lll}1 & 1 & 1 \\
0 & 0 & 0\end{array}$ \\
\hline 5 & $\oplus \oplus \oplus$ & & & - $\oplus \oplus$ & & $\begin{array}{l}0 \\
0\end{array}$ \\
\hline 6 & $\begin{array}{l}\oplus \oplus \\
\oplus \oplus \oplus\end{array}$ & 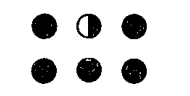 & $\begin{array}{l}0 \\
\oplus 0\end{array}$ & $\begin{array}{l}\oplus \oplus \\
\oplus \oplus \oplus\end{array}$ & & 6 \\
\hline
\end{tabular}

Remarks.
0 : Indicates one bird.
$O:$ Negative.
(1): Slightly positive.
(1) : Dead.
- Moderately positive.
: Markedly positive. 
Table 2. Course of microscopic lesions in laryngo-trachea (intra-ocular inoculation group)

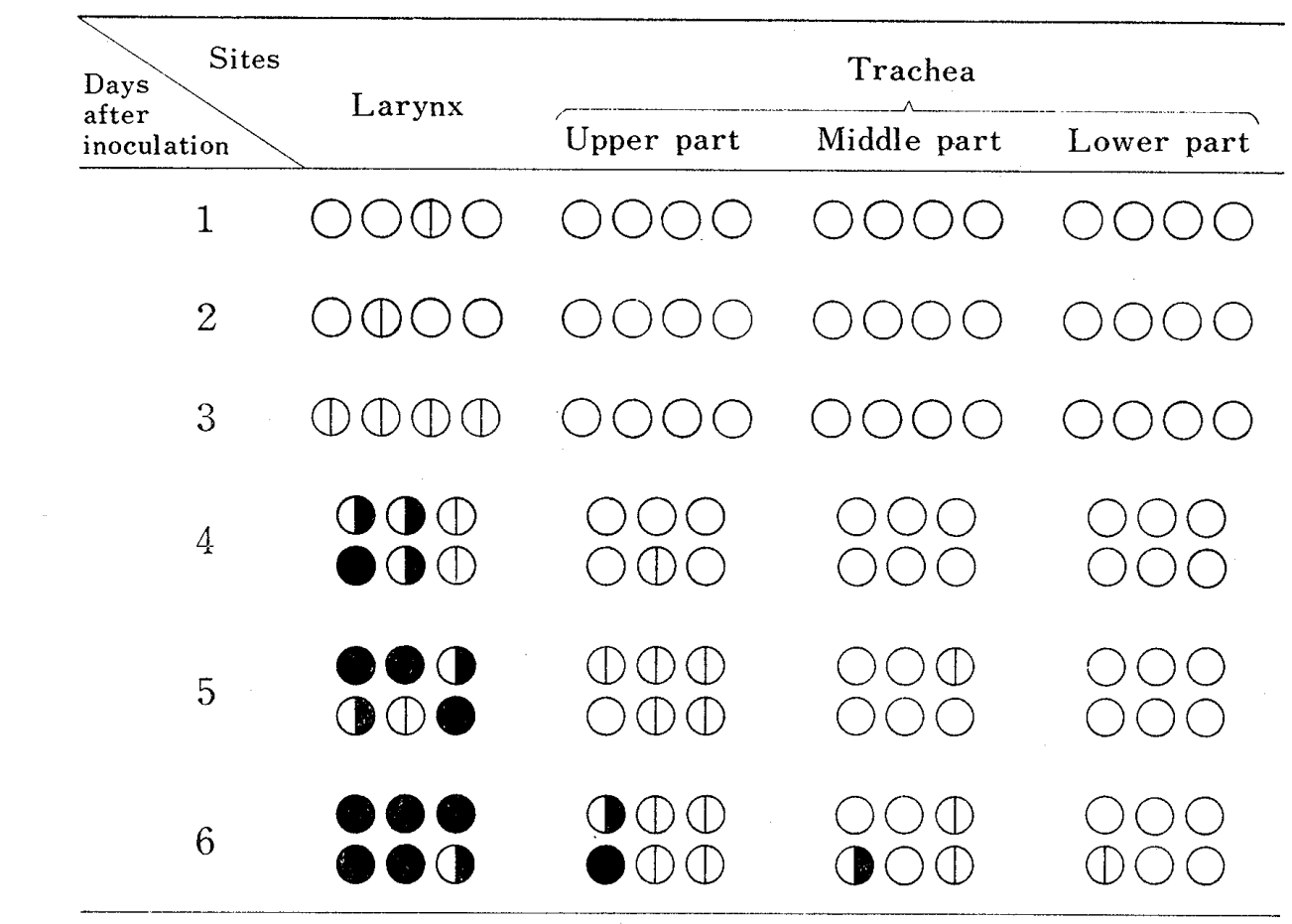

Remarks.

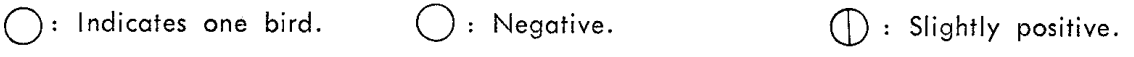

( ) Moderately positive. : Markedly positive.

Gross lesions detected were of hemorrhagic and necrotic nature. In chickens killed 4,5 and 6 days after inoculation, occasional diphtheric involvement of the larynx, trachea and conjunctiva was noticed, as well as typical hemorrhagic and/or necrotic lesions in the gastrointestines and lymphatic organs, such as the bursa of Fabricius, thymus and spleen.

Symptom and gross lesions at the sites studied of every bird are summarized in Table 1.

2. Micropathology and immunofluorescent studies

\section{Larynx}

Micropathology: Laryngeal lesions in birds having received intratracheal inoculation were similar to those induced intraocularly. Described are findings in birds injected intratracheally.
As shown in Table 2, the earliest lesions appeared in the larynx where lympatic tissues are normally abundant. This was followed by the appearance of lesions in the trachea descending from the upper part to the lower part.

Changes 1 and 2 days after inoculation

The initial change was characterized by vascular congestion and small foci of lymphatic cell-necrosis in lymphoid area. Sometimes edematous swelling was observed partially in the epithelium and mucous gland. A few heterophils were disseminated in those areas.

Changes at 3 days

Initial changes in the mucous gland were not noticed. Some parts of the gland involved fell into necrosis and vanished. Progress of degeneration in epithelial cells varied. Slightly degenerated cytoplasm swelled edematously and contained small 
vacuoles. The nuclear membrane of such cells stained densely with hematoxylin. The cytoplasm of moderately affected cells swelled edematously and contained large vacuoles. As a result, the involved cytoplasm was arranged like a network. The involved cells often contained eosinophilic inclusions, which looked to be round, club-like or amorphous inside the cytoplasm. In the most seriously affected cells, the cell-boundry disappeared and the cells themselves looked like basophilic or eosinophilic granules. Desquamation of the affected epithelium was often noted.

In the lymphoid area, lymphatic cells almost vanished and reticuloendothelial (RE) cells remained or proliferated. Degeneration and coagulation necrosis occured partially in small blood vessels accompanied with fibrinoid masses stained densely with eosin in the perivascular area.

Changes at 4, 5 and 6 days

The lesions found were similar to those observed 3 days after inoculation. There was no difference in progress of lesions among 6 birds killed on the same day.

Most part of the larynx of chickens sacrificed 5 and 6 days after inoculation showed marked desquamation or lack of the epithelium. Progressed changes were characterized by complete necrosis in the epithelial layer and lymphoid area. In contrast, there were some moderate cases in which most epithelium was retained and slight perivascular proliferation of immature lymphoid cells was observed.

In some cases, necrosis occurred in the striated mauscle layer surrounding the larynx.

Immunofluorescent findings: Disseminated fluorescent granules were observed in the cytoplasm of gland cells and the upper side of epithelial cells in samples collected 2 days after inoculation.
Three days after inoculation, cytoplasmic fluorescent granules appeared brightly. The fluorescence was brighter in gland cells than in epithelial cells. Many fluorescent foci were disseminated in the Iymphoid area. Fluorescence seemed to be present in the cytoplasm of RE cells.

Immunofluorescent findings on 4-day samples were similar to those on 3-day samples, except that less fluorescence was seen in the epithelium because of its desquamation.

\section{Trachea}

Microscopical lesions and immunofluorescent findings in the trachea were similar to those in the involved larynx.

\section{Conjunctiva}

Micropathology: Microscopic changes in the conjunctiva in birds inoculated intraocularly are described.

Changes 1 and 2 days after inoculation

There were no marked changes in the epithelial layer, except slight vacuole-formation inside the cytoplasm of epithelial cells. Although there was no distinct lesion in the epithelial layer, small and localized necrosis consisted of debris of lymphatic cells was found in the submucosal lymphoid area. Mild infiltration or proliferation of lymphoid cells was noted in the perivascular area. Heterophils were scattered throughout the lymphoid area and the epithelial layer.

In this stage, the lesion of the conjunctiva was generally restricted to the site of the Fornix conjunctivae.

Changes at 3 days

Moderate vacuole-formation in the cytoplasm was present in epithelial cells. The nuclear membrane of the cells stained densely with hematoxylin. Mild to moderate vanishment of lymphatic cells was 
noticed in the lymphoid area accompanied with many heterophils disseminated.

Changes at 4 days

Marked vacuolation in the cytoplasm was found in most epithelial cells. Desquamation of these cells was often observed. Eosinophilic inclusions resembling those in the laryngotracheal epithelium were present inside the cytoplasm. The nuclear membrane of these cells was stained densely with hematoxylin. In the epithelial layer, small spaces were often formed and sometimes contained necrotic products.

In the most severely affected cases, epithelial cells disappeared or disintegrated in the epithelial layer, and lymphatic cells vanished from the lymphoid area. Sometimes localized necrosis also destroyed RE cells. Many heterophils were disseminated throughout the epithelial layer and the lymphoid area. Partial necrosis of small blood vessels was often found. Homologous, eosinophilic and amorphous masses, which seemed to be fibrinoid, were deposited in the perivascular area. Marked hemorrhage was often found in the adjacent area.

Changes at 5 and 6 days

In addition to similar lesions observed in samples collected at 4 days, small necrotic foci were found in the squamous-cell layer.

Immunofluorescent findings: Three days after inoculation, fluorescent granules were found in the cytoplasm of some epithelial cells. A bright fluorescence was observed in the lymphoid areas of the conjunctiva 3 and 4 days after inoculation. The fluorescence in the lymphoid area seemed to be present in the cytoplasm of RE cells. Four days after inoculation the fluorescence of the lymphoid area was distributed through-

Fig. 1. Course of lesions in epithelia in larynx and conjunctiva
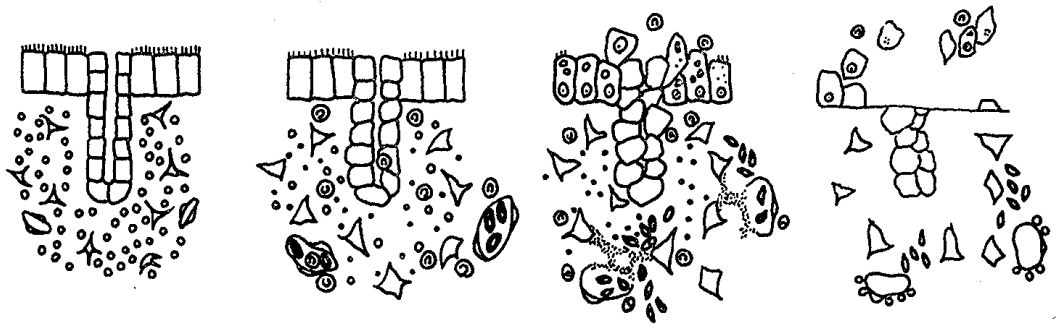

Course of fluorescent granule appearance
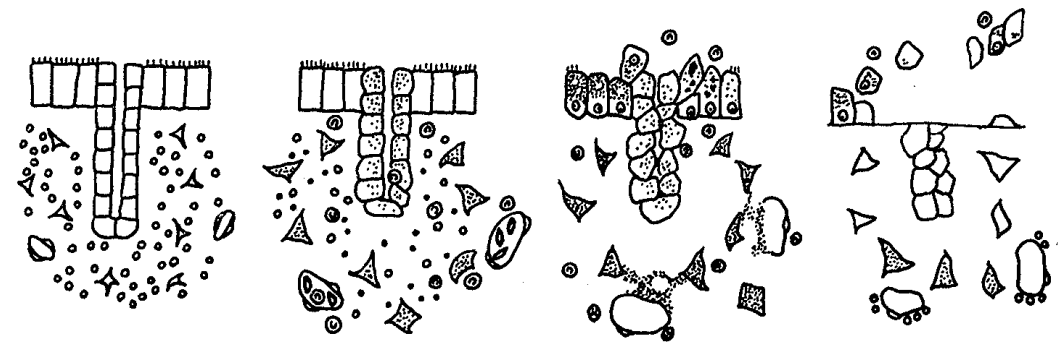

Remarks.

In conjunctiva the gland of this figure must be converted into goblet cells.
[1: Epithelial cell.
$A:$ Reficulum cell.
0 : Red cell.
$\square$ : Acinal cell of mucal gland.
(1): Heterophil.
0: Small blood vessel.
- : Lymphatic cell.
๑: Macrophage.
Upper: Fibrinoid mass.
Lower: Fluorescence. 
out this tissue. The intensity of fluorescence varied from sample to sample. Strong focal fluorescence was sometimes observed in the perivascular area and necrotic foci of the squamous cell layer.

The course of microscopic changes and immunofluorescent findings in the three organs are shown diagrammatically in

Table 3. Comparison between degrees of laryngo-tracheal and conjunctival lesions in two groups

\begin{tabular}{|c|c|c|c|c|}
\hline \multirow{2}{*}{$\begin{array}{l}\text { Groups } \\
\text { Days } \\
\text { after } \\
\text { inoculation }\end{array}$} & \multicolumn{2}{|c|}{$\begin{array}{l}\text { Intra-tracheal } \\
\text { inoculation group }\end{array}$} & \multicolumn{2}{|c|}{$\begin{array}{l}\text { Intra-ocular } \\
\text { inoculation group }\end{array}$} \\
\hline & Conjunctiva & Larynx & Conjunctiva & Larynx \\
\hline 1 & & & & \\
\hline 2 & $O$ & $D \oplus \mathbb{C}$ & O(1)(1) & \\
\hline 3 & $\bigcirc \oplus \bigcirc \bigcirc$ & & - (1) & (1) (1) \\
\hline 4 & & & & \\
\hline 5 & & & & \\
\hline 6 & & & & \\
\hline
\end{tabular}

Remarks.

: Indicates one bird.

※: Not examined.

: Negative.

(1): slightly positive.

(1) : Moderately positive.

: Markedly positive.

Table 4. Situation of fluorescent antibody in two groups

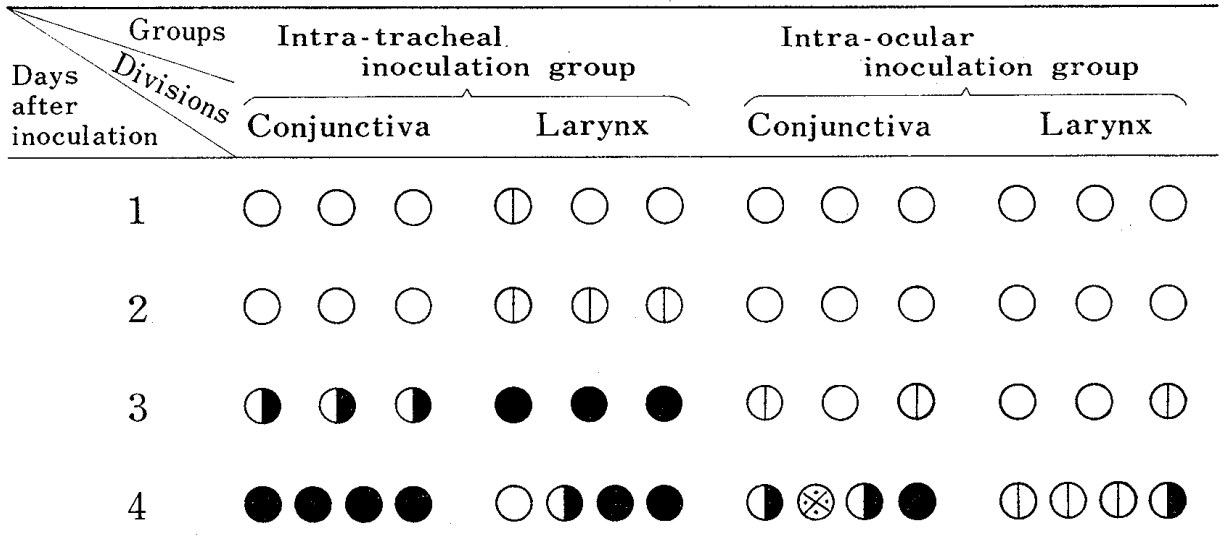

Remarks.
: Indicates one bird.
(1) Moderately positive.
(1) : slightly positive.
: Negative.
: Not examined.
: Markedly positive. 
Fig. 1 .

Situation of lesions and fluorescence in laryngotrachea and conjunctiva: Laryngotracheal lesions of the intratracheal inoculation group were found prior to the lesions in the conjunctiva, and vice versa in the intraocular inoculation group (Table 3).

In the fluorescent findings of the intratracheal inoculation group, the presence of viral antigen in the laryngotrachea was confirmed from the initial stage of infection. On the other hand, the conjunctival fluorescence of this group was not found on the same stage of infection. Fluorescence of detected sites was generally faint in intra-ocular inoculation group comparing with the intra-tracheal inoculation group (Table 4).

Acknowledgments: The author wishes to thank Dr. Akira Arakawa, of the Fujisawa Pharmaceutical Company Ltd., for review of this manuscript.

\section{References}

[1] Bradyl, C. A., and Hanson, R. P. (1965). Newcastle disease. In Diseases of Poultry, 5th ed., Biester H. E. and Schwarte L. H., editors. The Iowa State University Press, Ames, Iowa, 633.

[2] Fukushima, T. (1933). Zur Kenntnis der Hühnerpestpathologie. J. Jap. Soc. vet. Sci., 8, 147-169.

[3] Fukushima, T., and Shimomura, K. (1933). Beiträge zur pathologisch-anatomischen Kenn- tnis der farinasschen Avian pest, solchen wie der in Korea auftretenden Hünerseuche. $J$. Jap. Soc. vet. Sci., 7, 1-8.

[4] Gilles, D. K. (1954). Studies on the histopathology and pathogenesis of Newcastle disease of fowls in South Africa, with special reference to the lymphoid tissue. Onderstepoort J. vet. Res., 26, 599-629.

[5] Itakura, T., Yamagiwa, S., and Ono, T. (1971). Histopathological reactions in chickens infected with Newcastle disease virus. Jap. J. vet. Sci., 33, 277-289.

[6] Jungherr, E. L., Tizzer, E. E., Bradly, C. A., and Moses, H. E. (1946). The comparative pathology of fowl plague and Newcastle disease. Amer. J. vet. Res., 7, 250-288.

[7] Katoh, H. (1974). Pathological studies on Newcastle disease. Lymphatic lesions in the fogl with Asian type Newcastle disease. $J$. Jap. vet. med. Ass., 27, 175-182.

[8] Kawamura, A. (1970). Techniques of immunofluorescence. In Manual of Microbiological Tests (in Japanese), Igaku-Shoin, 695771 .

[9] Kawasaki, M., Miyamoto, T., Matsukata, Y., and Yanagi, S. (1968). Lesions of acute type Newcastle disease occurring in Miyazaki Prefecture. J. Jap. vet. med. Ass., 21, 113-118.

[10] Odagiri, Y., Taniguchi, T., Mochizuki, H., and Katoh, H. (1971). Laryngo-tracheal lesions caused by artificial Asian type Newcastle disease viruses. Jap. J. vet. Sci., 33, 278279.

[11] Ressang, A. A. (1961). Newcastle disease in Indonesia. II. Communicationes veterinariae, 5, 16-37.

[12] Tajima, M., Nagashima, H., and Ono, N. (1955). Pathological comparison between experimental Newcastle disease and fowl plague. Jap. J. vet. Sci., 17, 37. 


\section{Explanation of Figures}

Fig. 2. Bird showing a typical syndrome characterized by marked depression, green diarrhea, and edematous swelling in an area around the eyelid.

Fig. 3. Conjunctivae and tracheas of birds examined 4 days after intra-tracheal inoculation.

Fig. 4. The same organs as those in Fig. 2, 4 days after intraocular inoculation.

Figures 4,5 and 6 show laryngotracheal lesions of birds given intra-tracheal inoculation.

Fig. 5. Site of small focus where lymphatic cells vanished in lymphoid area of larynx, 2 days after inoculation. Hematoxylin and eosin (HE) staining. $\times 80$.

Fig. 6. Upper portion of trachea. Desquamation and formation of network inside the cytoplasm are marked in the epithelium, 4 days after inoculation. HE staining. $\times 320$.

Figures 7, 8, 9 and 10 show conjunctival lesions of birds given intra-ocular inoculation.

Fig. 7. Necrotic and hemorrhagic change accompanied with fibrinoid mass deposition around small blood vessels is marked throughout the trachea in this figure, 5 days after inoculation. HE staining. $\times 80$.

Fig. 8. Fibrinoid deposition around small blood vessels accompanied with infiltrative hemorrhage and vanishment of lymphatic cells, 3 days after inoculation. HE staining. $\times 160$.

Fig. 9. Desquamated epithelial cells showing a network inside the cytoplasm. Nuclear membranes of these cells are stained densely with hematoxylin, 4 days after inoculation. HE staining. $\times 800$.

Fig. 10. Perivascular fibrinoid mass deposition and marked edema in an area around the blood vessel, 4 days after inoculation. $\mathrm{HE}$ staining. $\times 160$.

Fig. 11. Necrotic focus in the squamous cell layer, 6 days after inoculation. HE staining. $\times 160$.

Fig. 12. Fluorescence in trachea of bird having received intratracheal inoculation, 4 days after inoculation. $\times 80$.

Fig. 13. Fluorescence in conjunctiva of bird having received intra-ocular inoculation, 4 days after inoculation. $\times 160$. 


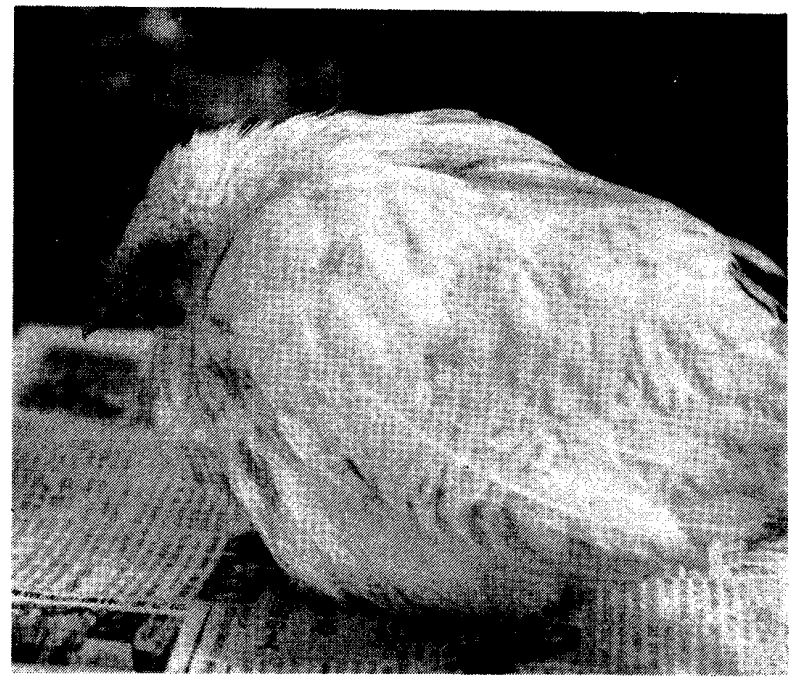

(2)

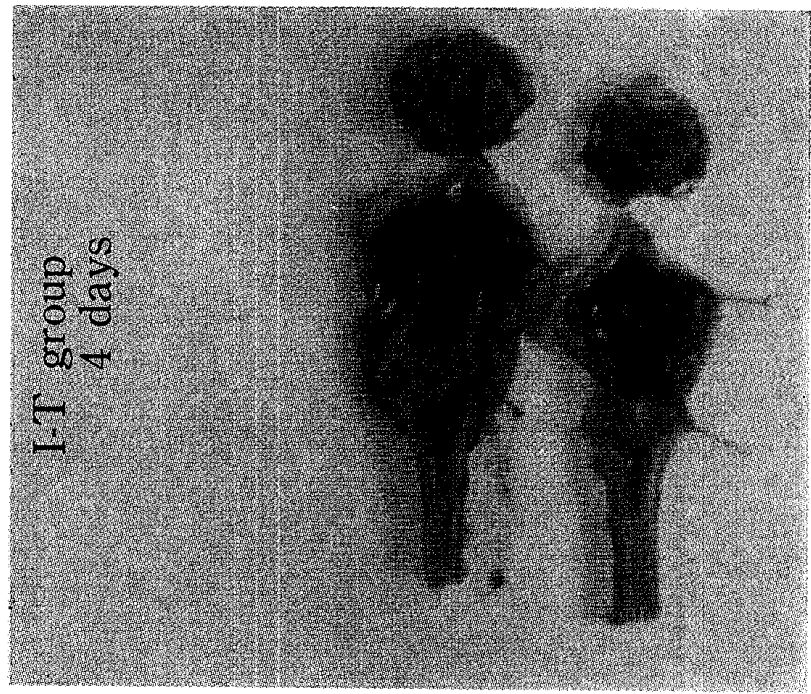

(3)

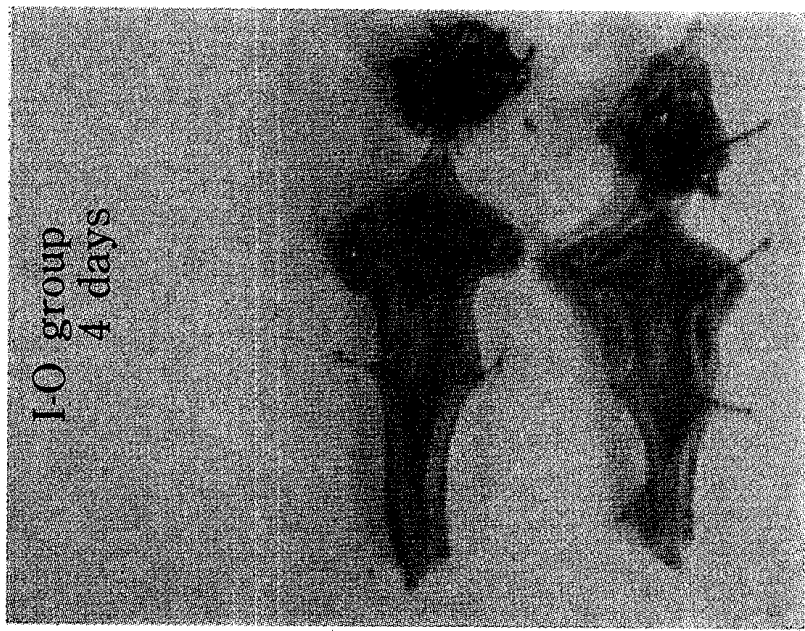

(4) 


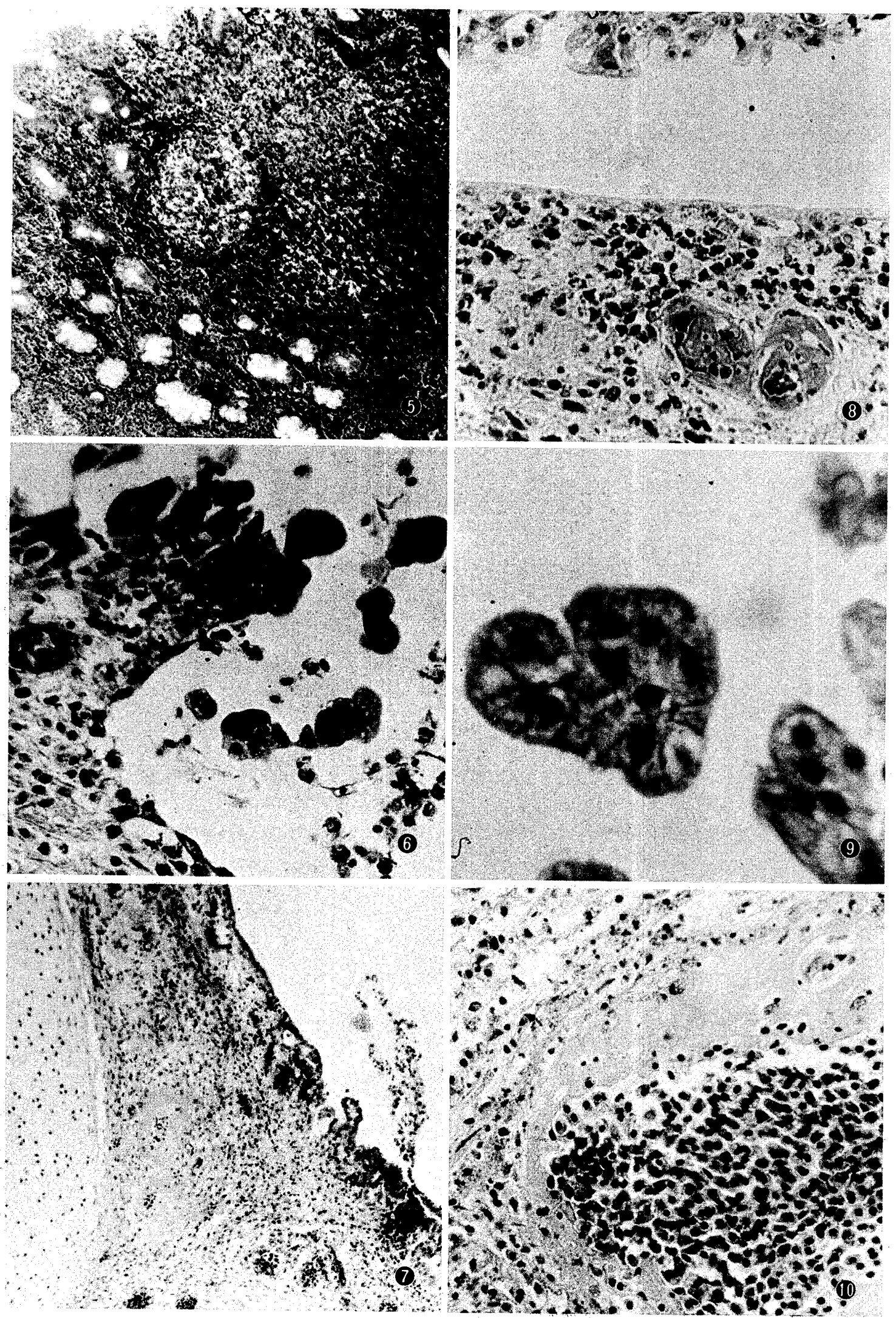



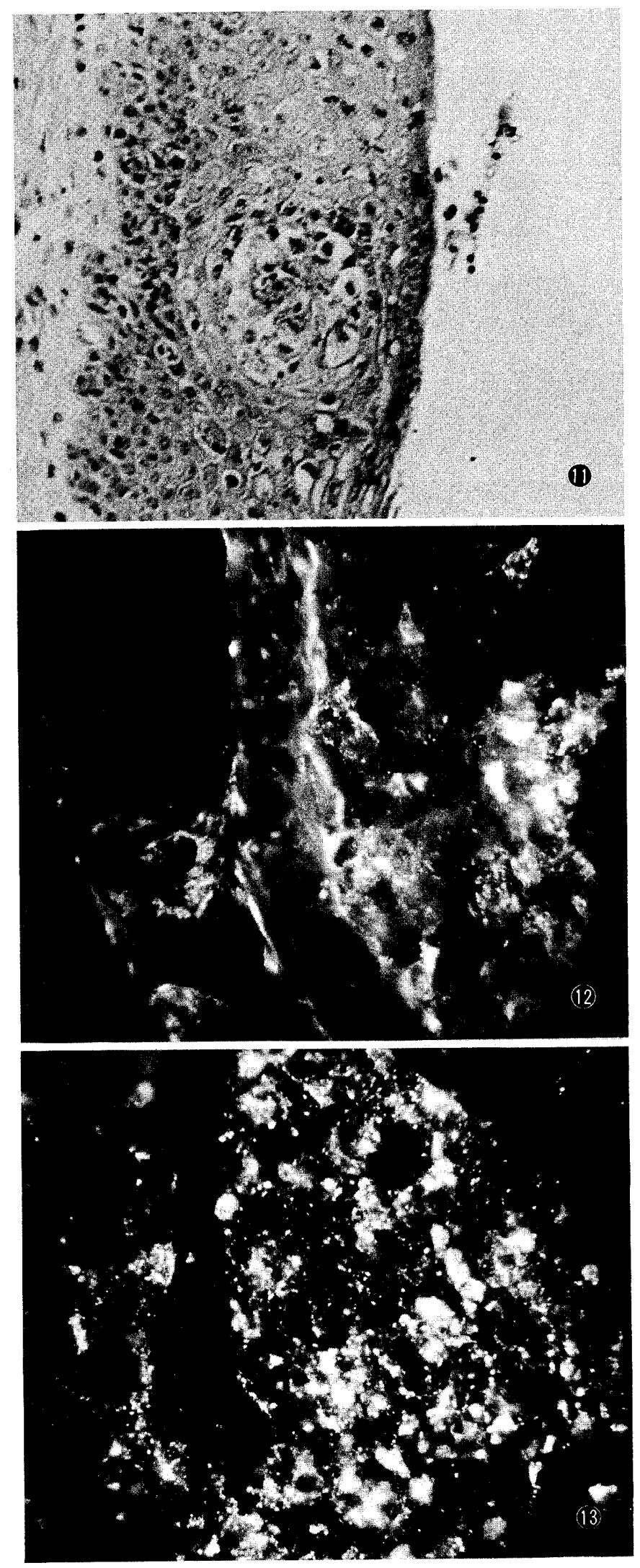